\title{
Aneurysmal Bone Cyst of Medial End of Clavicle in a Child, a Rare Case Report
}

\author{
Kumar C. Yashavntha • K. B. Nalini • Jagdish Menon • \\ D. K. Patro
}

Received: 24 October 2012 / Accepted: 24 March 2014 / Published online: 18 April 2014

(C) Indian Association of Surgical Oncology 2014

\begin{abstract}
Aneurysmal bone cyst is a locally aggressive benign tumor accounting for $3 \%$ of all benign bone tumors. It most commonly arises from ends of long bones and relatively rare in flat bones. Clavicle is a very rare site for bone tumors with secondaries more common than primaries. Very few cases of aneurysmal bone cyst have been reported in literature. We hereby report interesting and a rare case of aneurysmal bone cyst of medial end of clavicle in a eight year old lady which was treated with extended curettage and calcium sulfate bone grafting.
\end{abstract}

Keywords Aneurysmal bone cyst $\cdot$ Calcium sulfate $\cdot$ Clavicle

\section{Introduction}

Aneurysmal bone cyst is a benign but locally aggressive lesion of the bone which accounts for $3 \%$ of all bone tumors. It characterized by presence of spongy or multiloculated cystic tissue filled with blood. Up to $8 \%$ of aneurysmal bone cysts occur in skeletally immature patients who are under the age of 20 years (1-3). Most common locations include the proximal humerus, distal femur, proximal tibia, and spine but may

\footnotetext{
K. C. Yashavntha $(\bowtie) \cdot$ K. B. Nalini

M. S. R. Medical college, Bangalore, India

e-mail: kumyashwanth@gmail.com

K. B. Nalini

e-mail: drkbnalini@gmail.com

J. Menon • D. K. Patro

JIPMER, Puducherry, India

J. Menon

e-mail: jagdishmenon@yahoo.co.uk

D. K. Patro

e-mail: dkpatro@sify.com

involve any bone in the body. Clavicle is a very rare site for aneurysmal bone cyst with only few cases reported in literature (4). We hereby report an aneurysmal bone cyst of medial end of clavicle in a 6 year old girl.

Case Report

A 6 year old girl presented to us with a pain in the front of the chest for past 3 months which was gradually increasing. There was no history of trauma, fever or similar swellings in the other parts of the body. On examination there was a diffuse swelling over the left sternoclavicular joint. On palpation swelling was warm and tender. Shoulder movements on the left side were painless and free. Plain radiography revealed expansible, osteolytic lesion in the medial end of clavicle without a pathological fracture (Fig. 1).

The needle biopsy was done which ruled out malignancy. Patient was planned for curettage and bone graft. Under general anesthesia cortical window made anterior extended curettage of lesion with a diathermy was carried out (Fig. 2). The defect was filled with calcium sulfate mixed with allograft. Post operatively there were no complications. On regular follow up calcium sulfate was resorbed and new bone was formed. At 1 year follow cavity was consolidated with new bone (Figs. 3 and 4).

\section{Discussion}

As any other flat bone clavicle is a very unusual site for bone tumors and almost any bone tumor can arise from it. Secondaries are common than primary bone tumors. Review if literature shows clavicle accounts for less than $1 \%$ of all bone tumors. Rarity and 


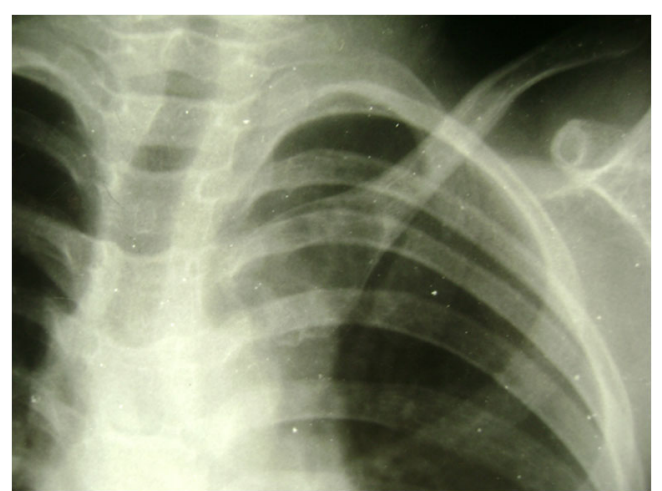

Fig. 1 Pre op radiograph showing osteolytic lesion in medial end of clavicle

variety of these lesions present a challenge to most orthopaedic surgeons. Hence knowledge about clavicular lesions will help with timely and appropriate management.

The term $\mathrm{ABC}$ was coined by Jaffe and Lichtenstein in 1942 based on its characteristic radiographic features (5). Aneurysmal bone cyst is a benign but locally destructive lesion of the bone characterized by presence of spongy or multiloculated cystic tissue filled with blood. It accounts for $2.5 \%$ of all bone tumors. Up to $8 \%$ of bone tumors occur in less than 20 years of age with peak incidence in second decade.

The differential diagnosis for aneurysmal bone cyst include giant cell tumor, chondromyxoid fibroma and telangiectatic osteosarcoma. Aneurysmal bone cyst has very unique and distinctive radiological features (6). It presents as an eccentric expansile osteolytic lesion of metaphysis with blowout or ballooned distension of the periosteum outlined by a paper-thin shell of subperiosteal bone. CT scan and MRI have been helpful in both making the diagnosis and determining the extent of the tumor and its relation to local anatomy. CT scans are particularly helpful in delineating the cyst in areas of complex anatomy, such as the spine or pelvis. In addition, the thin rim of bone surrounding the cyst can be identified (7). MRI shows the multiloculated cavities and fluid levels. When differentiating between a unicameral and aneurysmal bone cyst using MRI, the

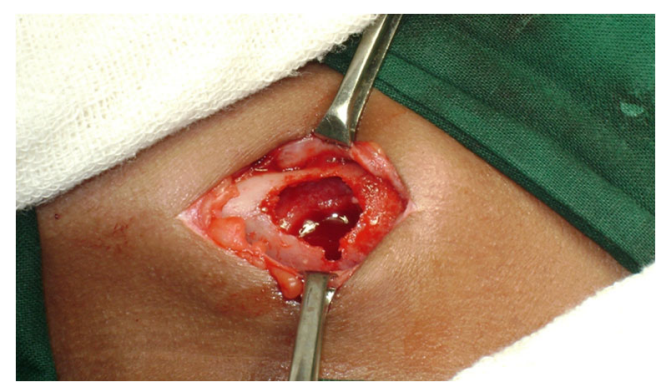

Fig. 2 Cavity after curettage

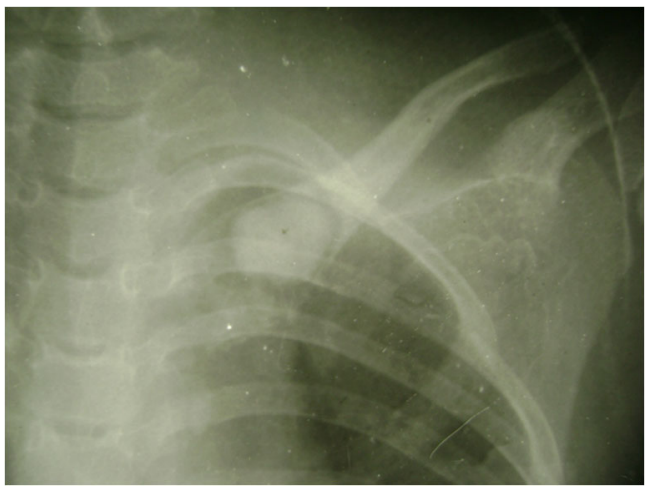

Fig. 3 Post operative radiograph after curettage and calcium sulfate grafting

presence of a double-density fluid level and intralesional septations usually indicates an aneurysmal bone cyst (8). It can arise de novo or in various other lesions, such as giant cell tumor, chondroblastoma, osteoblastoma, fibrous dysplasia, nonossifying fibroma, and chondromyxoid fibroma. Although the pathogenesis is uncertain, it is likely that aneurysmal bone cysts result from local circulatory disturbance leading to increased venous pressure and production of local hemorrhage. Grossly, an aneurysmal bone cyst is a cavitary lesion with blood-filled septate spaces.

Various treatment modalities have been suggested for aneurysmal bone cyst in literature like curettage, saucerisation, resection, radiotherapy, cryotherapy and vascular occlusion $(9,10)$. The standard treatment however is extended curettage and grafting with a bone graft substitute with or without allograft (11). Marginal resection sometimes is indicated for lesions in expendable bones like proximal fibula and distal ulna. Lesions in the spine or pelvis can be treated with preoperative embolization to minimize surgical blood loss. Arterial embolization has been used as definitive treatment of aneurysmal bone cysts in locations where curettage would be extremely difficult.

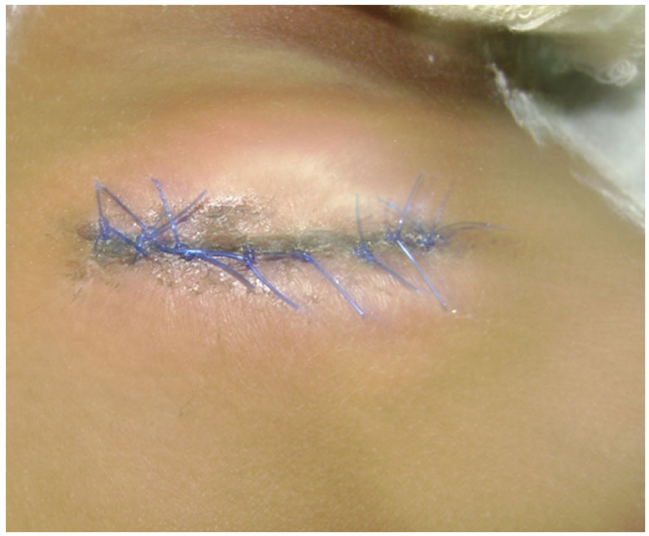

Fig. 4 Post op clinical photograph 


\section{Conflict of interest None.}

\section{References}

1. Dorfman HD, Czerniak B (1998) Cystic lesions. In: Dorfman HD, Czerniak B (eds) Bone tumors. Mosby, St. Louis, pp 855-879

2. Resnick D: Diagnosis of bone and Joint disorders 4th edition, W.B. Saunders com. 4037-4049

3. Smith J (1977) Aneurysmal bone cyst of clavicle. Br J Radiol 50: 706-709

4. Murphey MD, Andrews CL, Flemming DJ, Temple HT, Smith WS, Smirniotopoulos JG (1996) From the archives of the AFIP. Primary tumors of the spine: radiologic pathologic correlation. Radiographics $16: 1131-1158$
5. Campanacci M, Capanna R, Picci P (1986) Unicameral and aneurysmal bone cysts. Clin Orthop 204:25-36

6. Hudson TM (1984) Fluid levels in aneurysmal bone cysts: a CT feature. AJR Am J Roentgenol 142:1001-1004

7. Dorfman HD, Czerniak B (1998) Cystic lesions. In: Dorfman HD, Czerniak B (eds) Bone tumors. Mosby, St. Louis, pp $855-879$

8. Tillman B et al (1968) Aneurysmal bone cyst : an analysis of ninety five cases. Mayo Clin Proc 42:478-495

9. Marcove R et al (1995) Aneurysmal bone cyst. Clin Orthop 311:157163

10. Borreli $\mathrm{j}$ et al. : treatment of nonunions and osseous defects with bone graft and calcium sulphate, clin ortho rel res; 411, $245-254$

11. Mirzayan R et al (2001) The use of calcium sulphate in the treatment of benign bone lesions: a preliminary report. J Bone Joint Surg 83A: $355-358$ 